\title{
Exploring the Similarities between Complete and Initial Signatures of an Individual for the Purpose of Author Identification.
}

\author{
Bhoopesh Kumar Sharma, Pooja Prakash, Sharon Ann Philip
}

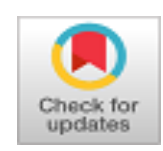

\begin{abstract}
Signature is a written depiction of someone's full name, nickname, or a simple letter that has been used on any desired document as an indication of their identity. It is a particular case of handwriting, which includes flourishes and special characters which are produced by the force of habit. Forensically, the signatures are examined for naturalness in execution and for consistent recurrent options that confirm the established practice pattern of the author and aids in the identification of the author in cases of disputes. Commonly used parameters for the signature analysis by the handwriting experts are the formation of the letters, alignment, embellishment, spacing, pen-lifts, pen-pauses, slant, initial \& final strokes, and pressure. In some instances where people make initials instead of full signatures, it becomes challenging for the forensics and handwriting experts to compare such initials with complete signatures. The present work has been focused on extracting the similarities between the initial and the complete signatures of an individual to aid in the identification of an individual in such complicated cases. This study may contribute to the identification of the author in the matter of disputes where initials have been used intentionally or unintentionally.
\end{abstract}

Index Terms: Signatures, Handwriting Characteristics, Author Identification, Initial Signatures

\section{INTRODUCTION}

Handwriting can be anything written, typed, inscribed, printed, or symbolized to transfer meaningful information to the recipient. It is a neuromuscular process that is coordinated by the brain; therefore, the handwriting legally can be described as 'Brain Writing' [1]. Based on the above fact, each has a specific writing habit that remains the same throughout life, after acquiring the stage of puberty until any external factors affect it.

Signature is a written depiction of someone's full name, nickname, or a simple letter that has been used on any desired

Revised Manuscript Received on October 30, 2019.

* Correspondence Author

Dr. Bhoopesh Kumar Sharma*, Department of Forensic Science, Amity University Dubai, UAE.

Ms. Pooja Prakash, Department of Forensic Science, Amity University Dubai, UAE.

Ms. Sharon Ann Philip, Department of Forensic Science, Amity University Dubai, UAE.

(C) The Authors. Published by Blue Eyes Intelligence Engineering and Sciences Publication (BEIESP). This is an open access article under the CC BY-NC-ND license (http://creativecommons.org/licenses/by-nc-nd/4.0/) document as an indication of their identity [2]. It is a special case of handwriting which includes flourishes and special characters which are produced by the force of habit [3]. When the forger tries to forge the signature, it doesn't follow the unconscious habit of the writer as everyone has got their own specific writing habit already coordinated which doesn't change until a serious affect has happened to the individual [4]. According to Y. M. Al-Omari Signature identification and verification system can be classified into two ways. Off-line \& on-line technique [5]. Off-line technique talks about collecting signature in a piece of paper and scanning the signature using computer to further visualize it. In an on-line technique the signature is itself signed on a digitizer and information such as speed pressure will be captured in addition [5].Previously in a study handwriting analysis has been done using a forensic tool, GRAPHJ which automatically detect the quantitative measurements of parameters such as the size of the letters, the position of 'I' dot, the shape of strokes, dimension of the words and letters and spacing using algorithms [6]. In another work, the similarities and dissimilarities on two different sets of handwriting by two different famous individuals from Indian history were studied. The parameters used by the researcher for comparison were movement, skill, slant, alignment, size, shading, pen pressure, and pen position. They concluded the coincidental similarities that are found among the signatures, which can further lead to an understanding of brains similar to neurotransmitters [7].Liwicki et al.; in 2014, studied on detecting forgeries either disguised or simulated from genuine signature using an automated system for signature identification and verification with the help of trained FHE's. They found that the simulations system produced excellent results, and the efficiency of automated system is as good as the manual human decisions [8].Initial Signatures are short signatures representing your full name, which is equally acceptable in a document like full signatures [9]. Mostly initial signatures are the first two letters of the name or a word that forms part of the phrase. People use initial signatures on documents as they have a very long name and hence give short forms for their names or uses the initial letter of their name as signature. Another reason to use an initial signature by people is to save time, especially seen among professionals such as doctors, professors, engineers, teachers, etc.The signatures are usually examined for naturalness in execution and for consistent recurrent options that confirm the established habit of the author. 


\section{Identification.}

Then the questioned signature is reviewed to ascertain the naturalness within the writing. After analyzing the parameters in both acknowledged and question signatures, they will be compared with each other. The parameters commonly used signature analysis and identification are alignments, embellishment, spacing, pen-Lifts, pen-Pauses, slant, the crossing of 'ts' \& dotting of 'i's, initial \& final strokes, and pen pressure [10].

Some people have got both full signatures and initial signatures. The purpose of the study was to find the similarities between full signatures and initial signatures so that these similarities can be used effectively by the handwriting expert in the identification of disputed authorship.

\section{MATERIALS \& METHODS}

The primary objectives of the present work were: a. To establish specific individual handwriting characteristics of an individual through their signatures,

b. To determine and compare the similarities between full signatures and initial signatures of a particular individual, and c. To perform the identification of the individual on the basis of initial signatures only.A total of 150 signature samples from 50 different adult male individuals were collected randomly at Amity University Dubai. The subjects were asked to provide the request specimen signature of three complete (full signature) and three initial signatures on an A4 size paper with the help of a ballpoint pen. The collected samples were then studied for various characteristic features like the formation of the letter, initial and ending strokes, writing alignment, connecting strokes; pen pauses, pen lifts, and any flourishment if present. The samples were analyzed using a magnifying glass $(10 \mathrm{x})$ and stereomicroscope under $50 \mathrm{X}$ for further enlargement to observe the minute details. The comparison of the class and individual characteristics were made manually using the identification parameters as described in "Handwriting Identification: Facts and Fundamentals" by Roy A. Huber \& A.M Headrick [10].

\section{OBSERVATIONS \& RESULTS}

As mentioned above, all the collected sample signatures (full and initial) were studied for the individual handwriting characteristic features. The characteristics have been identified and marked with different colored arrows (Figure 1 - 18). A careful comparative examination was made using magnifying glass and stereomicroscope to draw the observation. To summarize the observations, few of the samples have been mentioned below as shown in Table 1. 
Table 1: Representing selected samples and the comparison between the full and initial signatures of an individual

\begin{tabular}{|c|c|c|}
\hline $\begin{array}{l}\text { Sample Number } \\
\text { Selected for } \\
\text { Representation }\end{array}$ & Figures Description & $\begin{array}{l}\text { Characteristics Comparison and } \\
\text { Findings }\end{array}$ \\
\hline Sample- 1 & $\begin{array}{l}\text { Figure 2-3: Enlarged image comparison of the individual } \\
\text { characteristics of the full signatures (marked as S1F1) with } \\
\text { the initial signatures (marked as S1I1). }\end{array}$ & $\begin{array}{l}\text { 1. The initial stroke of Capital } \\
\text { Letter 'A' is curved } \\
\text { backwardly similar in both } \\
\text { cases of complete signature } \\
\text { and initial signature. } \\
\text { 2. The middle arm of letter 'A' } \\
\text { is starting proportionally at } \\
\text { the same position in both the } \\
\text { cases (full and initial } \\
\text { signatures). } \\
\text { 3. The Connective stroke of } \\
\text { pen pause drawing is } \\
\text { observed in both the cases } \\
\text { and is individual to the } \\
\text { writer. } \\
\text { 4. The alignment in both the } \\
\text { sets (full and initial) is } \\
\text { ascending (upward). } \\
\text { 5. There were specific pen lifts } \\
\text { seen while drawing the bar } \\
\text { of Capital Letter 'A' in both } \\
\text { the cases }\end{array}$ \\
\hline
\end{tabular}



Identification.

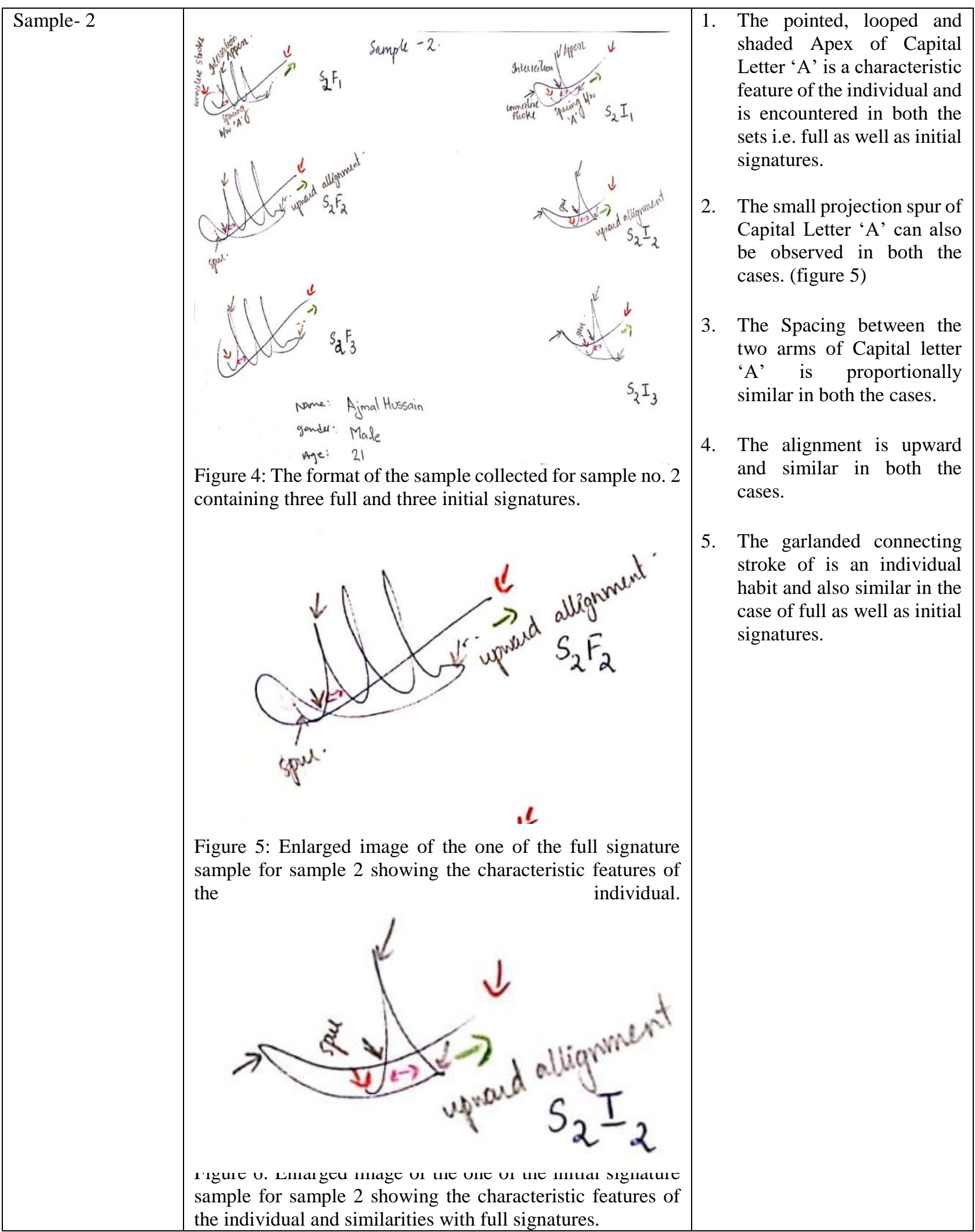




\begin{tabular}{|c|c|c|}
\hline Sample- 9 & $\begin{array}{l}\text { Figure 8: Enlarged image of the one of the full signature } \\
\text { sample for sample } 9 \text { showing the characteristic features of } \\
\text { the individual. }\end{array}$ & $\begin{array}{l}\text { 1. Initial Stroke of letter small } \\
\text { letter ' } \mathrm{f} \text { ' is curved and is } \\
\text { similar in both the complete } \\
\text { signatures and initial } \\
\text { signatures. } \\
\text { 2. The upper loop formation is } \\
\text { shaded made while writing } \\
\text { smaller letter ' } \mathrm{f} \text { ' is also } \\
\text { observed similar and can be } \\
\text { his/her natural habit of } \\
\text { writing. } \\
\text { 3. The connective stroke of } \\
\text { pen drawing seen in both } \\
\text { the cases can be seen. } \\
\text { 4. Pen pauses at the end of } \\
\text { both complete and initial } \\
\text { signatures are also observed } \\
\text { from the figure. } \\
\text { 5. The slant observed here is } \\
\text { left to vertical slant in both } \\
\text { the cases. } \\
\text { 6. The alignment is going } \\
\text { upward }\end{array}$ \\
\hline
\end{tabular}



Identification.

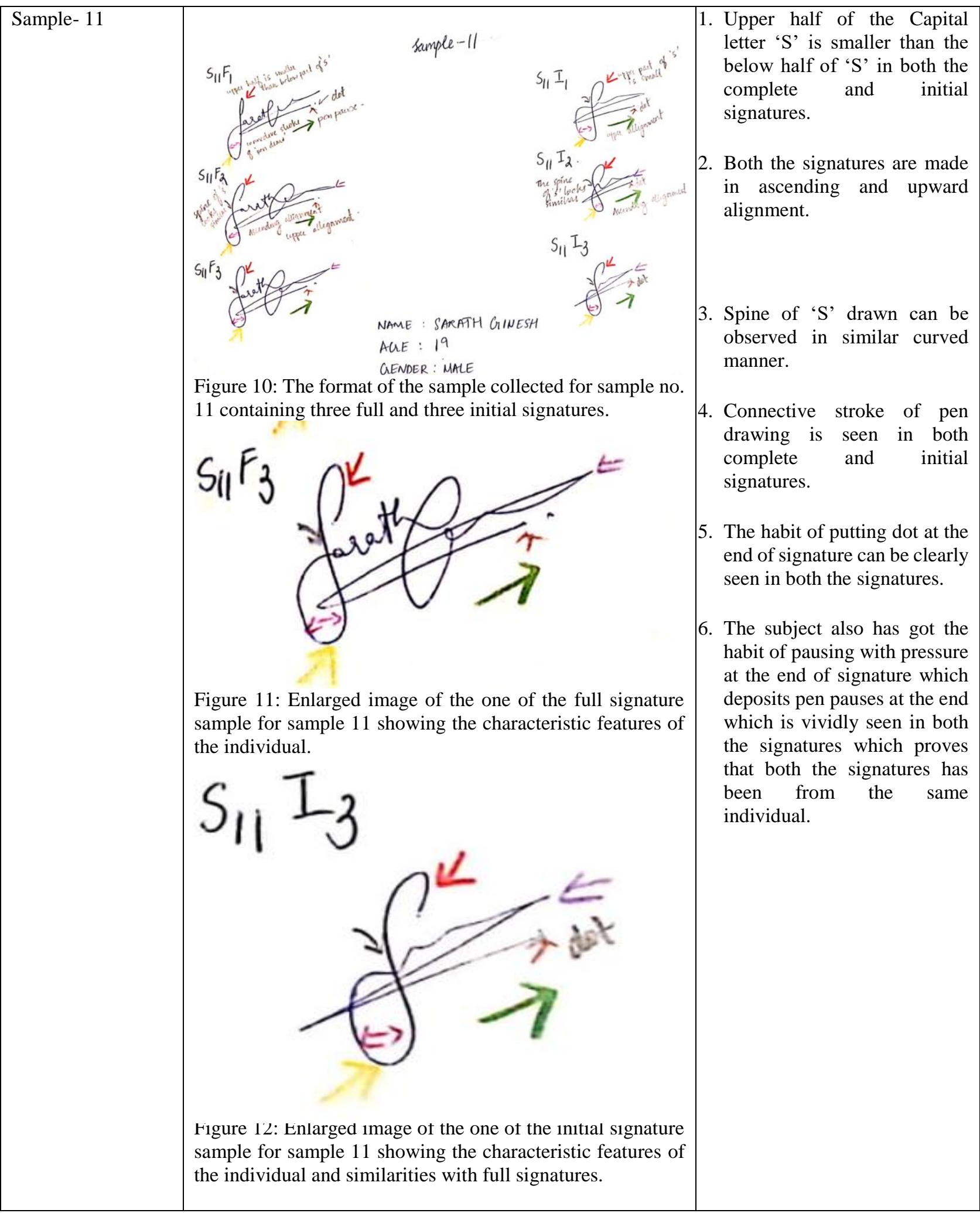




\begin{tabular}{|c|c|c|}
\hline Sample -13 & $\begin{array}{l}\text { Figure 14: Enlarged image of the one of the full signature } \\
\text { sample for sample } 13 \text { showing the characteristic features of } \\
\text { he individual. }\end{array}$ & $\begin{array}{l}\text { 1. Initial stroke of small letter } \\
\text { ' } h \text { ' ca be observed in both the } \\
\text { complete and initial } \\
\text { signatures } \\
\text { 2. The upper loop of small } \\
\text { letter 'h' is also a habit of } \\
\text { person seen in both the } \\
\text { signatures. } \\
\text { 3. Connective stroke of pen } \\
\text { drawing can be observed in } \\
\text { both the cases } \\
\text { 4. The slant seen in both the } \\
\text { cases are right to vertical } \\
\text { slant which is a subconscious } \\
\text { habit of the person. }\end{array}$ \\
\hline
\end{tabular}



Identification.

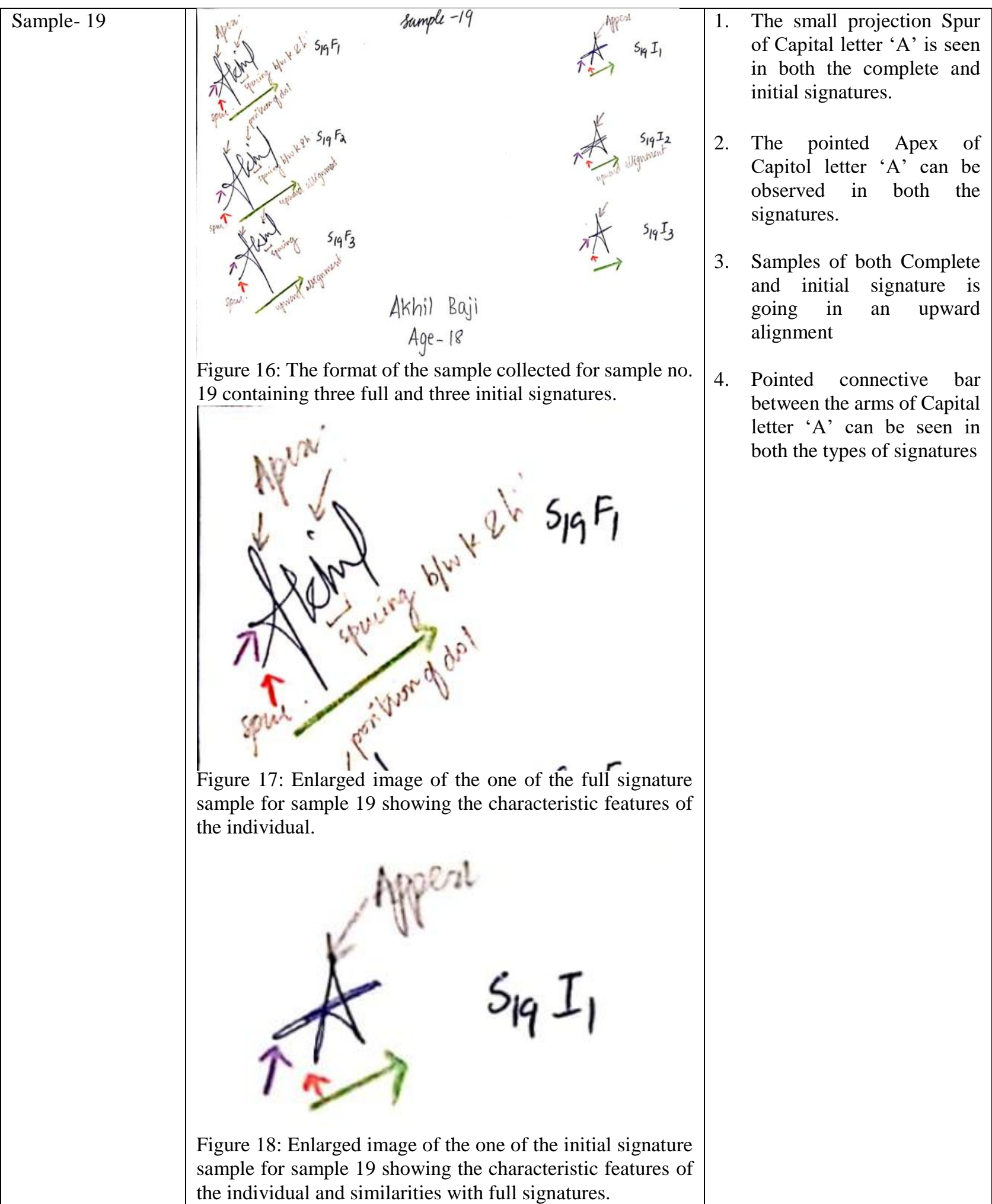




\section{DISCUSSION}

Signatures are the personal identity of an individual. We all use our signatures every day several times for many official and ono-official purposes. Worldwide, many cases of signature forgeries are reported daily, and most of them encountered in financial transactions. Many times, people do proxy signatures for others [11]. Also, it has been noticed that most of the population uses two types of signatures i.e., full or complete signatures representing their names and initial signatures (short form) in their routine day to day affairs [12]. If such cases of initial signatures are disputed, then it becomes difficult for the forensic handwriting and signature analyst to compare these with full signatures and to reach any decisive conclusions. As a rule of analysis like has to be compared with like, in such cases initials should be compared with initials and full signatures should be compared with full [13] but problem arises when the full specimen signatures or admitted writing samples are not available, and the expert has to try to compare the full signatures with initials. The scope of present work was to study the minute individual similarities among the full and initial signatures of the individuals to aid in the identification of the author of the signature.In the study, it was observed that certain characteristic features of handwriting are repeatedly the same in full as well as initial signatures. Characteristics like the formation of the initial letter, connecting writing strokes, spurs, curves, the formation of strange shaded and unshaded loops, proportional size of the letters in respect to others, base alignment, individual flourishes, and writing slant. All these features may serve in the inclusive identification of the author. However, this may be further difficult if the act of disguise has been inculcated deliberately [14].

\section{CONCLUSION}

Based on the study, it can be concluded that there exists a number of similarities between the complete and initial signatures of an individual. The similarities that can be commonly seen in both complete and initial signatures are alignment, speed, slant, specific natural habit of the person especially in the formation of individual letters, pen lifts and pen pause within certain words or letters, spacing between individual letters, doting after signature, initial, final \& connective strokes.The principle of handwriting identification states that no two signatures are written exactly alike is related to the concept that each writer has a natural range of variation. This has also been observed in the present study. However, with the careful examination of individual writing characteristics, it is possible to an extent to compare two different (full and initial) sets of signatures, if made by the same person. However, handwriting experts examine patterns in signatures to establish a range of variation of a writer; the pattern needs to be established in several comparison samples. It was also concluded that this work has got certain limitations and future scope of work as discussed. One of the basic limitations was that when the expert doesn't find his/her expertise in language from the exemplars collected then the expert finds it challenging to study the similarity between written characteristics of the complete and initial signature. On the other hand, when the subject has used completely different writing characters in full and initial signature, it becomes difficult for the expert to find the similarity to prove or disprove the authenticity of signatures.

\section{REFERENCE}

1. Why handwriting is brain-writing. (2019). Retrieved from http://www.sundayobserver.lk/2018/04/01/thoughts/why-handwritingbrain-writing

2. Willard, V. (2018). Forensic Document Examination. Journal of Forensic Document Examination, 24, 67-71.

3. Liwicki, M., Heuvel, C.E., Found, B., \& Malik, M.I. (2010). Forensic Signature Verification Competition 4NSigComp2010 - Detection of Simulated and Disguised Signatures. 2010 12th International Conference on Frontiers in Handwriting Recognition, 715-720.

4. Bajaj, R., \& Chaudhury, S. (1997). Signature verification using multiple neural classifiers. Pattern Recognition, 30(1), 1-7. doi: 10.1016/s0031-3203(96)00059-3

5. Al-Omari, Y., Abdullah, S., \& Omar, K. (2019). State-of-the-art in offline signature verification system. 10.1109/ICPAIR.2011.5976912.

6. Guarnera, L., Farinella, G., Furnari, A., Salici, A., Ciampini, C., Matranga, V., \& Battiato, S. (2018). Forensic analysis of handwritten documents with GRAPHJ. Journal Of Electronic Imaging, 27(05), 1. doi: 10.1117/1.jei.27.5.051230

7. Mishra, V., Agarwal, N., Shukla, S., \& Mishra, M. (2015). A critical study on standard parameters of handwriting examination - similarities and dissimilarities. International Journal Of Multidisciplinary Research And Development, 2(4), 201-204.

8. Liwicki, M., Heuvel, C.E., Found, B., \& Malik, M.I. (2010). Forensic Signature Verification Competition 4NSigComp2010 - Detection of Simulated and Disguised Signatures. 2010 12th International Conference on Frontiers in Handwriting Recognition, 715-720.

9. Williams, E. (2019). What Is the Difference between Signature and Initials. $\quad$ Retrieved from https://pdf.wondershare.com/signature/initial-signature.html

10. Huber, R., \& Headrick, A. (1999). Handwriting identification. Boca Raton, Fla.: CRC Press.

11. Yap, W., \& Goi, B. (2014). Forgery attacks of an identity-based multi-proxy signature scheme. International Journal Of Communication Systems, 29(2), 283-289. doi: 10.1002/dac.2828

12. Signature Analysis | Handwriting Analysis. (2019). Retrieved from http://atozhandwriting.com/signature-analysis/

13. Evidence. Comparison of Handwriting. Admissibility of Relevant Handwriting When Prejudicial. (1923). The Yale Law Journal, 33(2), 205. doi: $10.2307 / 789429$

14. Bird, C., Found, B., Ballantyne, K., \& Rogers, D. (2010). Forensic handwriting examiners' opinions on the process of production of disguised and simulated signatures. Forensic Science International, 195(1-3), 103-107. doi: 10.1016/j.forsciint.2009.12.001 


\section{AUTHORS PROFILE}

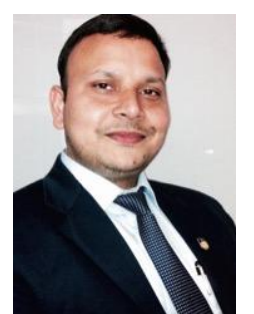

Dr. Bhoopesh Kumar Sharma, Ph.D. (Chemistry) is an Assistant Professor and Programme Head, Forensic Science at Amity University Dubai with 14+ years of experience in Teaching, Research and project supervision in various

areas of Forensic Science including fingerprints, questioned document analysis, ballistics, and crime scene investigation. Has solved a large number of civil and criminal cases and given Forensic opinion in Indian and abroad court cases in various areas like Handwriting, signature, Bank Frauds Investigation, thefts, murder mysteries, etc. Have presented and published many Research Papers in National and International Conferences / Seminars/ Workshop/Journals of repute.

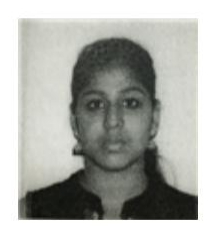

Ms. Pooja Prakash, Student of Bachelors of Forensic Science at Amity University Dubai. She has undergone a number of training in the area of questioned document analysis and signature verification. She has also completed this project under the guidance of Dr. Bhoopesh Kumar Sharma.

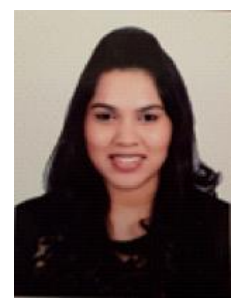

Ms. Sharon Ann, Philip, Masters in Forensic Science from University of Kent, UK. Working as Forensic Instructor at Amity University Dubai and has been trained by Advanced Security Academy, Milan Italy. Also undergone in training to operate various instruments such as Scanning Electron Microscope, Nuclear Magnetic Resonance, X-ray Diffraction, X-ray Fluorescence, Spectroscopy from University of Kent, UK. 